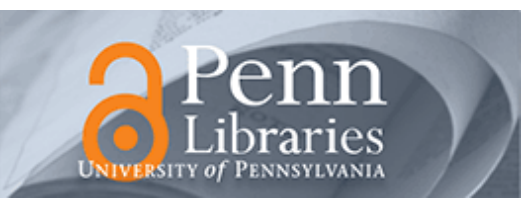

University of Pennsylvania

ScholarlyCommons

8-2006

\title{
Safety in Nonhuman Primates of Ocular AAV2-RPE65, a Candidate Treatment for Blindness in Leber Congenital Amaurosis
}

Samuel G. Jacobson

University of Pennsylvania, jacobsos@mail.med.upenn.edu

Sanford L. Boye

Tomas S. Aleman

University of Pennsylvania, aleman@mail.med.upenn.edu

Thomas J. Conlon

Caroline J. Zeiss

See next page for additional authors

Follow this and additional works at: https://repository.upenn.edu/vet_papers

Part of the Veterinary Medicine Commons

\section{Recommended Citation}

Jacobson, S. G., Boye, S. L., Aleman, T. S., Conlon, T. J., Zeiss, C. J., Roman, A. J., Cideciyan, A. V., Schwartz, S. B., Komáromy, A. M., Doobrajh, M., Cheung, A. Y., Sumaroka, A., Pearce-Kelling, S. E., Aguirre, G. D., Kaushal, S., Maguire, A. M., Flotte, T. R., \& Hauswirth, W. W. (2006). Safety in Nonhuman Primates of Ocular AAV2-RPE65, a Candidate Treatment for Blindness in Leber Congenital Amaurosis. Human Gene Therapy, 17 (8), 845-858. http://dx.doi.org/10.1089/hum.2006.17.845

This paper is posted at ScholarlyCommons. https://repository.upenn.edu/vet_papers/80

For more information, please contact repository@pobox.upenn.edu. 


\title{
Safety in Nonhuman Primates of Ocular AAV2-RPE65, a Candidate Treatment for Blindness in Leber Congenital Amaurosis
}

\begin{abstract}
Leber congenital amaurosis (LCA) is a molecularly heterogeneous disease group that leads to blindness. LCA caused by RPE65 mutations has been studied in animal models and vision has been restored by subretinal delivery of AAV- RPE65 vector. Human ocular gene transfer trials are being considered. Our safety studies of subretinal AAV-2/2. RPE65 in RPE65 -mutant dogs showed evidence of modest photoreceptor loss in the injection region in some animals at higher vector doses. We now test the hypothesis that there can be vector-related toxicity to the normal monkey, with its human-like retina. Good Laboratory Practice safety studies following single intraocular injections of AAV-2/2. RPE65 in normal cynomolgus monkeys were performed for 1-week and 3-month durations. Systemic toxicity was not identified. Ocular-specific studies included clinical examinations, electroretinography, and retinal histopathology. Signs of ocular inflammation postinjection had almost disappeared by 1 week. At 3 months, electroretinography in vector-injected eyes was no different than in vehicle-injected control eyes or compared with presurgical recordings. Healed sites of retinal perforation from subretinal injections were noted clinically and by histopathology. Foveal architecture in subretinally injected eyes, vector or vehicle, could be abnormal. Morphometry of central retina showed no photoreceptor layer thickness abnormalities occurring in a dose-dependent manner. Vector sequences were present in the injected retina, vitreous, and optic nerve at 1 week but not consistently in the brain. At 3 months, there were no vector sequences in optic nerve and brain. The results allow for consideration of an upper range for no observed adverse effect level in future human trials of subretinal AAV-2/2. RPE65. The potential value of foveal treatment for LCA and other retinal degenerations warrants further research into how to achieve gene transfer without retinal injury from surgical detachment of the retina.
\end{abstract}

\section{Keywords}

Leber congenital amaurosis, blindness, mutated dogs, retina, injection, dogs

\section{Disciplines}

Medicine and Health Sciences | Veterinary Medicine

\section{Author(s)}

Samuel G. Jacobson, Sanford L. Boye, Tomas S. Aleman, Thomas J. Conlon, Caroline J. Zeiss, Alejandro J. Roman, Artur V. Cideciyan, Sharon B. Schwartz, András M. Komáromy, Michelle Doobrajh, Andy Y. Cheung, Alexandar Sumaroka, Susan E. Pearce-Kelling, Gustavo D. Aguirre, Shalesh Kaushal, Albert M. Maguire, Terence R. Flotte, and William W. Hauswirth 


\title{
Safety in Nonhuman Primates of Ocular AAV2-RPE65, a Candidate Treatment for Blindness in Leber Congenital Amaurosis
}

\author{
SAMUEL G. JACOBSON,${ }^{1}$ SANFORD L. BOYE, ${ }^{2}$ TOMAS S. ALEMAN,${ }^{1}$ THOMAS J. CONLON,${ }^{3}$ \\ CAROLINE J. ZEISS, ${ }^{4}$ ALEJANDRO J. ROMAN, ${ }^{1}$ ARTUR V. CIDECIYAN, ${ }^{1}$ SHARON B. SCHWARTZ, 1 \\ ANDRAS M. KOMAROMY ${ }^{5}$ MICHELLE DOOBRAJH, ${ }^{1}$ ANDY Y. CHEUNG, ${ }^{1}$ \\ ALEXANDER SUMAROKA, ${ }^{1}$ SUSAN E. PEARCE-KELLING, ${ }^{6}$ GUSTAVO D. AGUIRRE, ${ }^{5}$ \\ SHALESH KAUSHAL, ${ }^{2}$ ALBERT M. MAGUIRE, ${ }^{1}$ TERENCE R. FLOTTE, ${ }^{3}$ \\ and WILLIAM W. HAUSWIRTH ${ }^{2,3}$
}

\begin{abstract}
Leber congenital amaurosis (LCA) is a molecularly heterogeneous disease group that leads to blindness. LCA caused by RPE65 mutations has been studied in animal models and vision has been restored by subretinal delivery of AAV-RPE65 vector. Human ocular gene transfer trials are being considered. Our safety studies of subretinal AAV-2/2.RPE65 in RPE65-mutant dogs showed evidence of modest photoreceptor loss in the injection region in some animals at higher vector doses. We now test the hypothesis that there can be vectorrelated toxicity to the normal monkey, with its human-like retina. Good Laboratory Practice safety studies following single intraocular injections of AAV-2/2.RPE65 in normal cynomolgus monkeys were performed for 1-week and 3-month durations. Systemic toxicity was not identified. Ocular-specific studies included clinical examinations, electroretinography, and retinal histopathology. Signs of ocular inflammation postinjection had almost disappeared by 1 week. At 3 months, electroretinography in vector-injected eyes was no different than in vehicle-injected control eyes or compared with presurgical recordings. Healed sites of retinal perforation from subretinal injections were noted clinically and by histopathology. Foveal architecture in subretinally injected eyes, vector or vehicle, could be abnormal. Morphometry of central retina showed no photoreceptor layer thickness abnormalities occurring in a dose-dependent manner. Vector sequences were present in the injected retina, vitreous, and optic nerve at 1 week but not consistently in the brain. At 3 months, there were no vector sequences in optic nerve and brain. The results allow for consideration of an upper range for no observed adverse effect level in future human trials of subretinal AAV-2/2.RPE65. The potential value of foveal treatment for LCA and other retinal degenerations warrants further research into how to achieve gene transfer without retinal injury from surgical detachment of the retina.
\end{abstract}

\section{OVERVIEW SUMMARY}

Ocular gene therapy has emerged as a potential treatment modality for many incurable human genetic retinal diseases. As preclinical evidence of success mounts, the need for translational research increases. An autosomal recessive retinal blindness caused by a defect in the retinoid (visual) cycle, Leber congenital amaurosis caused by RPE65 gene mutations, has become the target disease for a number of groups worldwide for the first subretinal gene transfer trial in man. The present paper builds on the substantial foundation of $\mathrm{dog}$ and rodent proof-of-concept, dose efficacy,

\footnotetext{
${ }^{1}$ Department of Ophthalmology, Scheie Eye Institute, University of Pennsylvania, Philadelphia, PA 19104.

${ }^{2}$ Department of Ophthalmology, University of Florida, Gainesville, FL 32610.

${ }^{3}$ Powell Gene Therapy Center, Genetics Institute, and Departments of Pediatrics, Pathology, and Pharmaceutics, University of Florida, Gainesville, FL 32610.

${ }^{4}$ Section of Comparative Medicine, Yale University School of Medicine, New Haven, CT 06520.

${ }^{5}$ Section of Medical Genetics, School of Veterinary Medicine, University of Pennsylvania, Philadelphia, PA 19104.

${ }^{6}$ James A. Baker Institute for Animal Health, Cornell University, Ithaca, NY 14853.
} 
and safety data with rAAV-2/2.RPE65. Questions about systemic and retinal toxicity are asked in a nonhuman primate, the only mammal with a foveate retina like that of humans, to determine whether there is sufficient safety to initiate human clinical trials.

\section{INTRODUCTION}

$\mathbf{L}$ EBER CONGENITAL AMAURosis (LCA) is the clinical diagnosis given to a group of early-onset retinal blinding diseases caused by mutations in many different genes (Cremers et al., 2002; Preising and Heegaard, 2004). Naturally occurring and genetically engineered animal models of a number of the molecular forms of LCA have been studied. Animal models of three different forms have already been successfully treated with ocular gene transfer by subretinal injection (e.g., Acland et al., 2001; Batten et al., 2005; Pawlyk et al., 2005).

The largest amount of preclinical data assembled to date has been on the form of LCA due to mutations in the RPE65 gene. RPE65 is the isomerohydrolase in the retinal pigment epithelium (RPE) cells and it catalyzes the critical step in the visual cycle converting all-trans-retinyl ester to 11-cisretinol and permitting normal photoreceptor function and vision to occur (Redmond et al., 1998, 2005; Rando, 2001; Thompson and Gal, 2003; Jin et al., 2005; Moiseyev et al., 2005). Restoration of vision to blind eyes of large and small animals with RPE65 deficiency has occurred by subretinal delivery of RPE65-expressing recombinant adeno-associated virus (rAAV)-based vector (Acland et al., 2001, 2005; Narfstrom et al., 2003; Dejneka et al., 2004; Lai et al., 2004; Jacobson et al., 2005; Pang et al., 2006). The relationship of the phenotype in the animal models to that in the human retinal disease caused by RPE65 mutations was found to be similar enough to justify consideration of a clinical trial (Jacobson et al., 2005). Dose efficacy of subretinal rAAV2/2.RPE65 in RPE65-mutant dogs was also determined and the highest $1.5 \log$ units of vector doses used were efficacious (Jacobson et al., 2006). Safety studies in these dogs and investigations in normal rats showed no evidence of systemic toxicity. Localized retinal toxicity evident by ocular histopathology, however, was observed in the dogs and it was postulated to have a vector dose-independent component due to surgical trauma and a vector dose-related thinning of the outer retina. The latter was present in some but not all dogs that received the two highest vector doses used (Jacobson et al., 2006).

The present work examines safety of subretinal rAAV2/2.RPE65, specifically with the two highest vector doses, in normal nonhuman primates. The importance of these experiments in the scheme of preclinical investigations is that the monkey retina is human-like in organization and, unlike other mammals, the monkey shares with humans a specialized central region of high cone photoreceptor density known as the fovea (Polyak, 1941; Curcio et al., 1990; Provis et al., 2005). A short-term (1-week) study of 6 monkeys and a longer term (3-month) study of 11 monkeys after ocular gene transfer to the central retina were performed and systemic and ocular toxicity was evaluated.

\section{MATERIALS AND METHODS}

\section{Animals and ocular surgery}

Normal cynomolgus monkeys ( $n=17$; age, approximately 2 years; weights, $1.8-2.6 \mathrm{~kg}$ ) were studied under Good Laboratory Practice (GLP)-compliant protocols. The ocular surgical procedures for subretinal and intravitreal injections were performed with sterile instruments, surgical fields, and solutions; methods were similar to previously described work (Bennett et al., 1999) except that three sclerotomy incisions were made. A lid speculum was placed and a radial conjunctival peritomy incision was made in the right-hand superior quadrant. The pars plana region sclerotomy site was marked on the external sclera. Three separate 27-gauge sclerotomy incisions were made in the following locations: in the bed of the prepared sclera (right-hand superior quadrant), in the opposite (left-hand superior) quadrant, and in the inferotemporal quadrant. An anterior chamber paracentesis was performed with a 30-gauge needle introduced via the limbal cornea. A sterile contact lens coupling solution was applied to the corneal surface. A sterile Machemer fundus contact lens was then placed into position. Using coaxial illumination and direct visualization through an operating microscope, the shaft of the subretinal injector was introduced through the right-handed superior quadrant sclerotomy into the midvitreous cavity. An extendable 41-gauge cannula was positioned so that it was apposed to the retinal surface at an oblique angle. The retina was draped over the cannula tip; the retinal surface was penetrated, avoiding injury to the RPE and choroid. Test article or vehicle was injected to confirm that the tip was not occluded and was properly positioned. If necessary, it was repositioned. The remaining volume of the test article or vehicle was injected to achieve the total volume. The injector was removed. All studies were in accordance with the ARVO Statement for the Use of Animals in Ophthalmic and Vision Research (Association for Research in Vision and Ophthalmology, Rockville, MD) and institutional approval.

\section{rAAV-RPE65 vector production, purification, and characterization}

Details of the production, purification, and characterization have been published (Jacobson et al., 2006).

\section{Clinical assessments}

Mortality and clinical observation. The animals were observed on a daily basis with attention to signs of change in behavior/activity, food consumption, fecal/urinary output, general habits, and skin/hair changes. Weights were obtained weekly and at termination.

Ophthalmic examinations. Monkeys had ophthalmic examinations before dosing, at 1 day, 1 week, and then at 1,2 , and 3 months postinjection. The examinations included slit lamp biomicroscopy, indirect ophthalmoscopy, and measurement of intraocular pressure (Tono-Pen Vet; Medtronic Ophthalmics, Jacksonville, FL).

\section{Electroretinography}

Monkeys ( $n=11)$ had full field bilateral simultaneous electroretinograms (ERGs) before and 3 months after ocular sur- 
gery; protocols conformed to the International Society for Clinical Electrophysiology of Vision standards for human ERG recordings (Marmor et al., 2004). Animals were dark-adapted for $>3 \mathrm{hr}$ before testing. Anesthesia, given under dim red light, was with intramuscular ketamine- $\mathrm{HCl}(10 \mathrm{mg} / \mathrm{kg})$ and xylazine $(0.5 \mathrm{mg} / \mathrm{kg})$. Corneas were anesthetized with topical proparacaine- $\mathrm{HCl}(1 \%)$ and pupils were dilated (6-8 $\mathrm{mm}$ diameter) with topical tropicamide (1\%) and phenylephrine (10\%). Body temperature was maintained with an electric heating pad. Recordings were performed with a computer-based system (Diagnosys, Littleton, MA). Burian-Allen bipolar contact lens electrodes (Hansen Ophthalmic, Coralville, IA) were used. The protocol is similar to a previously published protocol used for human studies (Jacobson et al., 1989, 1995) and included responses under four conditions, two dark-adapted and two lightadapted. A dark-adapted rod ERG b-wave was obtained with a 0.025 (scotopic) $\mathrm{cd} \cdot \mathrm{sec} \cdot \mathrm{m}^{-2}$ blue flash. A dark-adapted, mixed cone and rod ERG was elicited with a standard white flash of 5.77 (photopic) $\mathrm{cd} \cdot \mathrm{sec} \cdot \mathrm{m}^{-2}$. After this, a light-adapting white background of 34 (photopic) $\mathrm{cd} \cdot \mathrm{m}^{-2}$ was presented for $5 \mathrm{~min}$. Cone ERGs were then recorded with the standard white flash presented at $1 \mathrm{~Hz}$ on the same background, and with 29-Hz flicker on a 6.9 (photopic) $\mathrm{cd} \cdot \mathrm{m}^{-2}$ white background. A- and b-wave amplitudes and timing were quantified conventionally (Jacobson et al., 1989, 1995). Light level calibrations were performed before test sessions, using an integrating photometer with photopic and scotopic filters (IL1700; International Light, Peabody, MA). Acquisition stage amplitude and timing calibration were verified externally before the sessions, using a calibration device (2506; LKC Technologies, Gaithersburg, MD). Differences between sessions for each eye, and between eyes for each session were compared on the basis of paired $t$ tests.

\section{Clinical pathology}

Serum chemistry, hematology. Peripheral venous blood was collected for hematology and serum chemistry. Hematology parameters included red blood cell count and morphology, hemoglobin, hematocrit, and white blood cell and platelet counts. Serum chemistries included blood urea nitrogen, creatinine, alanine aminotransferase, aspartate aminotransferase, alkaline phosphatase, bilirubin, total protein, albumin, globulin, calcium, sodium, potassium, chloride, glucose, total iron, cholesterol, and triglycerides.

Anti-AAV2 antibody assays. Serum samples from the monkeys receiving either a subretinal or intravitreal injection of vector were assayed for circulating antibodies to the AAV2 capsid proteins. For the 1-week study, serum samples were collected on days 0,2 , and 8 . For the 3-month study, sera were collected on days $0,8,30$, and 90 postinjection. Briefly, 96-well plates were coated with $1.2 \times 10^{9}$ AAV2 particles/well overnight at $4^{\circ} \mathrm{C}$. A wash with phosphate-buffered saline (PBS)-Tween was followed by blocking for $2 \mathrm{hr}$ at $37^{\circ} \mathrm{C}$ with $10 \%$ fetal bovine serum (Cellgro; Mediatech, Herndon, VA). After a $1 \times$ wash with PBS-Tween, samples and a known positive human standard were diluted between 1:10 and 1:10,240 and allowed to bind overnight at $4{ }^{\circ} \mathrm{C}$. Each sample was run in triplicate. Washing was followed by addition of the detection antibody at a di- lution of 1:50,000 (goat anti-human immunoglobulin, conjugated with horseradish peroxidase [HRP]; Biosource International, Camarillo, CA) for $2 \mathrm{hr}$ at $37^{\circ} \mathrm{C}$. Finally, the plate was washed and exposed to tetramethylbenzidine (TMB) peroxidase detection substrate (KPL, Gaithersburg, MD) and read at $450 \mathrm{~nm}$ with an enzyme-linked immunosorbent assay (ELISA) plate reader (Molecular Devices, Sunnyvale, CA). Sample antiAAV2 titers were then read relative to a human standard curve derived from the same plate.

\section{Necropsy and histopathology}

A complete gross necropsy was performed and non-ocular tissues were sampled for histopathology in both 1-week and 3month studies. Slides from nonocular tissues were prepared and interpreted by Charles River Laboratories, Preclinical Services, Pathology Associates (Chicago, IL).

Ocular tissue handling at necropsy in the two studies. An emphasis of the longer duration study on quantitative ocular histopathology led to some differences in procedure between the 1-week and 3-month studies (detailed below).

Study I (duration, 1 week): At necropsy, the eyes were enucleated. The anterior segment was removed and divided for biodistribution and histopathology studies. When tissues were collected for biodistribution, appropriate precautions were taken to avoid cross-contamination. The eyecup was cut vertically through the region of subretinal injection (guided by fundus drawings of the animals). The calotte including the fovea and optic nerve was designated for histopathology (immersion fixed in Bouin's solution). For the remaining and more temporal calotte, retina was separated from the RPE-choroid-sclera and submitted for biodistribution studies. A vitreous sample and the optic nerve tissue proximal to the globe were also used for biodistribution studies. The remaining intraorbital optic nerve was designated for histopathology. Regions of the brain, with special attention paid to the visual pathways, were dissected and submitted as paired samples: one for biodistribution and one for histopathology.

Study II (duration, 3 months): At necropsy, the eyes were enucleated and the optic nerve was removed at the point at which it exits the globe. The optic nerve most proximal to the globe was used for biodistribution studies and the remainder of the intraorbital optic nerve was designated for histopathology. The intact globe was immersion fixed in Bouin's solution for histopathology. As with the 1-week study, regions of the brain with attention to the visual pathways were dissected and submitted as paired samples: one for biodistribution and one for histopathology.

Ocular histopathology. Histological examination was performed on 5- $\mu \mathrm{m}$ paraffin-embedded sections stained with hematoxylin and eosin. Unstained sections were studied by immunocytochemistry in study II only. Preparation of slides of ocular tissues was performed by Research Pathology Services (Doylestown, PA). Details of how the eyes were divided for sectioning are as follows.

Study I (duration, 1 week): Sections were examined from the optic nerve, anterior segment, superior temporal retina (site of subretinal injection in six eyes), inferior temporal retina, and 
nasal retina. All retinal sections were from the portion of the eyecup designated for histopathology (see above). The tissue was first divided by a vertical cut nasal to the optic nerve, leaving a calotte that included the fovea (and superior injection region in right eyes) and optic nerve, and a second calotte of nasal retina. The more temporal calotte was then divided into two blocks by a horizontal cut inferior to the fovea (leaving the superior temporal region that included the injection site and an inferior temporal region). The remaining nasal calotte was not further divided.

Study II (duration, 3 months): The intact globe was divided using two vertical cuts: one nasal to the optic nerve (about 2 $\mathrm{mm}$ ) and one temporal to the fovea (about $4 \mathrm{~mm}$ temporal to the optic nerve). Sections were taken from the resulting three calottes (described as central, temporal, and nasal). The central calotte (including fovea and superior injection region and corresponding inferior region) was cut toward the nasal retina until the foveal depression was identified. The temporal calotte (including part of injection region) was cut further into the temporal retina. The nasal calotte was cut further into the nasal retina.

Morphometry in study II. Vertical sections from the central calotte that crossed near the foveal depression, and from the temporal and nasal calottes, were used for morphometry using methods and strategy as in previous work (e.g., La Vail et al., 2000; Hare et al., 2004; Leung et al., 2005). Contiguous fields, extending from the central retina into the far superior and inferior retina, were imaged at $\times 10$ magnification with a camera (Olympus BH2; Olympus America, Melville, NY) attached to a microscope (Leica DFC480; Leica Microsystems, Bannockburn, IL). At least 60 viewing field images extending from the centralmost retina into the superior and inferior retina were digitized, scaled with a calibration tool (Graticules, Tonbridge, Kent, UK) and montaged with image-editing software (Adobe Photoshop 6.0; Adobe Systems, San Jose, CA). Measurements were made on montaged images with imaging software (Spot 4.0.9; Diagnostic Instruments, Sterling Heights, MI). Outer nuclear layer (ONL) thickness was measured at 500- $\mu$ m intervals. ONL thickness results for the untreated left eyes (LEs) were compared with results from vehicle-injected or vector-injected right eye (RE) samples.

Immunocytochemistry was performed as previously described (Acland et al., 2005). Slides from vertical sections of each eye were incubated with RPE65 PETLET antibody (diluted 1:5000; gift of T.M. Redmond, Laboratory of Retinal Cell and Molecular Biology, National Eye Institute, National Institutes of Health, Bethesda, MD). Negative controls were serial sections of the positive slides and were incubated with the primary antibody omitted.

\section{Vector biodistribution}

Procedures for biodistribution studies have been described (Song et al., 2002; Jacobson et al., 2006). In brief, $1 \mu \mathrm{g}$ of extracted genomic DNA was used in all quantitative polymerase chain reactions (PCRs); reaction conditions followed those recommended by PerkinElmer/Applied Biosystems (Foster City, $\mathrm{CA}$ ) and included 50 cycles of $94^{\circ} \mathrm{C}$ for $40 \mathrm{sec}, 37^{\circ} \mathrm{C}$ for $2 \mathrm{~min}$, $55^{\circ} \mathrm{C}$ for $4 \mathrm{~min}$, and $68^{\circ} \mathrm{C}$ for $30 \mathrm{sec}$. Primer pairs were de- signed to the cytomegalovirus (CMV) enhancer/chicken $\beta$-actin promoter as described (Donsante et al., 2001) and standard curves were established by spike-in concentrations of a plasmid DNA (CBAT) carrying the same promoter as above and the $\alpha_{1}$-antitrypsin cDNA (Song et al., 2002). DNA samples were assayed in triplicate. The third replicate was spiked with CBAT DNA at a ratio of 100 copies/ $\mu \mathrm{g}$ of genomic DNA. If at least 40 copies of the spike-in DNA were detected, the DNA sample was considered acceptable for reporting vector DNA copies. When the copy number of the vector DNA found in that sample was $\geq 100$ copies $/ \mu \mathrm{g}$, the sample was considered positive and the measured copy number per microgram was reported. The sample was considered negative if $<100$ copies $/ \mu \mathrm{g}$ were present. When $<1 \mu \mathrm{g}$ of genomic DNA was analyzed to avoid PCR inhibitors copurifying with DNA in the extracted tissue, the spike-in copy number was reduced proportionally to maintain the 100 copies/ $\mu$ g DNA ratio.

\section{RESULTS}

Two studies of different durations in nonhuman primates (Table 1) were performed to determine the safety of intraocular injections of $\mathrm{rAAV}-2 / 2 . R P E 65$. The vector used in both studies is denoted as rAAV2-CB ${ }^{\mathrm{SB}}-\mathrm{h} R P E 65$ (Jacobson et al., 2006). Sequencing of the plasmid DNA used to make the vector confirmed that it contained two AAV2 inverted terminal repeats that surround a regulatory element composed of the CMV immediate-early enhancer, chicken $\beta$-actin promoter with first intron/exon junction, hybrid chicken $\beta$-actin, and rabbit $\beta$-globin intron/exon junction, followed by a human RPE65 cDNA, and the simian virus 40 (SV40) polyadenylation signal. In both studies, right eyes (REs) received a single intraocular injection and left eyes (LEs) served as controls. All subretinal (SR) injections were in the superior posterior retina (Fig. 1). The results of clinical systemic and ocular examinations and clinical pathology of both 1-week and 3-month studies are presented together; results of pathology and vector biodistribution are presented individually for the two studies.

\section{Mortality, clinical observations, and clinical pathology}

Monkeys with ocular injections of rAAV-2/2.RPE65 or vehicle control remained clinically healthy for the duration of the experiments. There were no early deaths and no clinical signs of toxicity noted during the study. There were no test articlerelated effects on food consumption and no changes in body weight. There were also no test article-related changes in hematology or clinical chemistry parameters.

\section{Ocular examinations}

In vivo assessments of preretinal ocular structures at four time points postinjection are summarized in Fig. 2 for the 17 monkeys. Abnormalities were graded at three levels of severity. After mild conjunctival reactions at 1 day in 6 of the 17 monkeys, there was no clinical evidence of conjunctival abnormality at 1 week postinjection. Corneal changes, specifically mild punctate keratopathy in the inferior cornea, were present at both time points. Anterior chamber flare (scored as mild) was noted in six monkeys (all vector treated) at 1 day and in only 
Table 1. Characteristics of Nonhuman Primates and Ocular Doses of rAAV2-CB ${ }^{\mathrm{SB}}-\mathrm{h} R P E 65$ INJECTED

\begin{tabular}{|c|c|c|c|c|}
\hline Animal (no.) & Gender & $\begin{array}{l}\text { Injection } \\
\text { route }\end{array}$ & $\begin{array}{l}\text { Vector dose } \\
\text { (relative) }^{\mathrm{a}}\end{array}$ & $\begin{array}{c}\text { Vector genomes } \\
\text { delivered }\left(\times 10^{10}\right)^{\mathrm{a}}\end{array}$ \\
\hline \multicolumn{5}{|c|}{ Study I (1 week) } \\
\hline M1 (20515) & $\mathrm{F}$ & SR & 0 & 0 \\
\hline M2 (20564) & M & SR & 0 & 0 \\
\hline M3 (20507) & $\mathrm{F}$ & SR & $1 \times$ & 150 \\
\hline M4 (20566) & M & SR & $1 \times$ & 150 \\
\hline M5 (20480) & $\mathrm{F}$ & SR & $3 \times$ & 300 \\
\hline M6 (20552) & M & SR & $3 \times$ & 330 \\
\hline \multicolumn{5}{|c|}{ Study II (3 months) } \\
\hline M7 (20877) & M & SR & 0 & 0 \\
\hline M8 (20547) & M & SR & 0 & 0 \\
\hline M9 (C06987) & $\mathrm{F}$ & SR & 0 & 0 \\
\hline M10 (20730) & M & SR & $1 \times$ & 150 \\
\hline M11 (C06992) & $\mathrm{F}$ & SR & $1 \times$ & 150 \\
\hline M12 (C08913) & $\mathrm{F}$ & SR & $1 \times$ & 150 \\
\hline M13 (20777) & M & SR & $3 \times$ & 450 \\
\hline M14 (20732) & M & SR & $3 \times$ & 450 \\
\hline M15 (C09033) & $\mathrm{F}$ & SR & $3 \times$ & 450 \\
\hline M16 (20725) & M & IV & $1 \times$ & 150 \\
\hline M17 (20747) & M & IV & $3 \times$ & 450 \\
\hline
\end{tabular}

Abbreviations: SR, subretinal; IV, intravitreal.

${ }^{\mathrm{a}} 0$, vehicle injected; $1 \times, 1.0 \times 10^{10} \mathrm{vg} / \mu \mathrm{l}$ (injections were $150 \mu \mathrm{l}$ in volume, except in $\mathrm{M} 5,100$ $\mu \mathrm{l} ; \mathrm{M} 6,110 \mu \mathrm{l})$.

two monkeys (including one vehicle control) at 1 week. Mild lens changes were noted in one vector-treated (intravitreal) monkey at 1 day (mild posterior capsular opacity) and in two vector-treated (subretinal) monkeys at 1 week (mild anterior capsular opacity, possibly related to the paracentesis procedure). Vitreous cells were seen in three of five vehicle control eyes at 1 day and in two vector-treated eyes at 1 week. By 2 months, there were no detectable abnormalities and this was also the case at 3 months after surgery.

Funduscopic abnormalities at 1 day after surgery in eyes with subretinal injections showed mainly persistence of elevated retina, and small intraretinal hemorrhage and RPE changes at or near the retinotomy site. Surrounding uninjected retina was normal in appearance. By 1 week, many of the eyes showed either flattening of the retina or less prominent elevations. The region of initially injected retina, even if no longer elevated, appeared discolored and demarcated from surrounding uninjected retina. Examinations 1, 2, and 3 months after surgery revealed persistent RPE changes or atrophic scars at or near the retinotomy site and demarcation lines between injected and uninjected retina. There was no distinguishable difference between vehicle-injected or vector-injected eyes in the prominence of such findings. Eyes with intravitreal injections had normalappearing fundi.

\section{Retinal electrophysiology}

Retinal toxicity was evaluated by electroretinography (ERG). ERGs were performed pre- and 3 months posttreatment in both eyes of the 11 monkeys in study II (Fig. 3). Rep-

FIG. 1. Drawings of the ophthalmoscopic appearance of the monkey retina (right eye) and the superior central sites of the subretinal injections of vehicle control (A) and vector $(\mathbf{B}) .+$, foveal location.
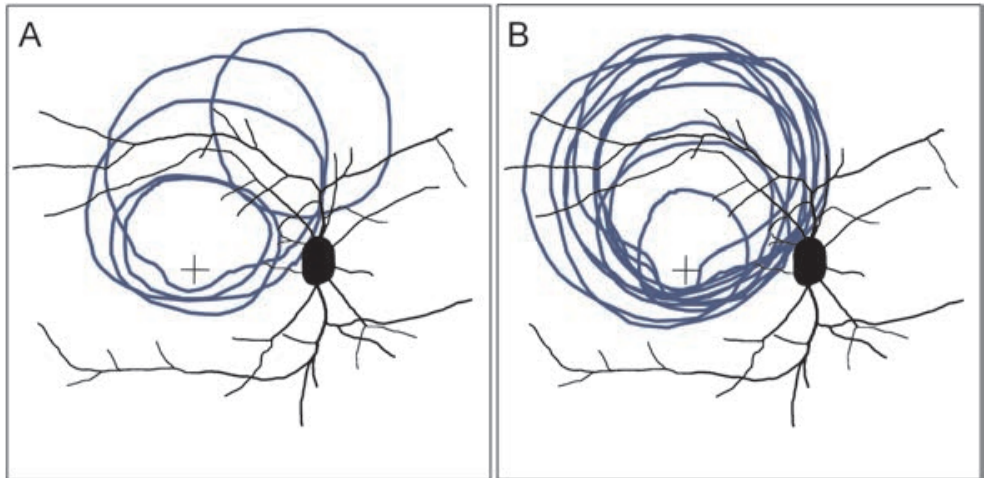

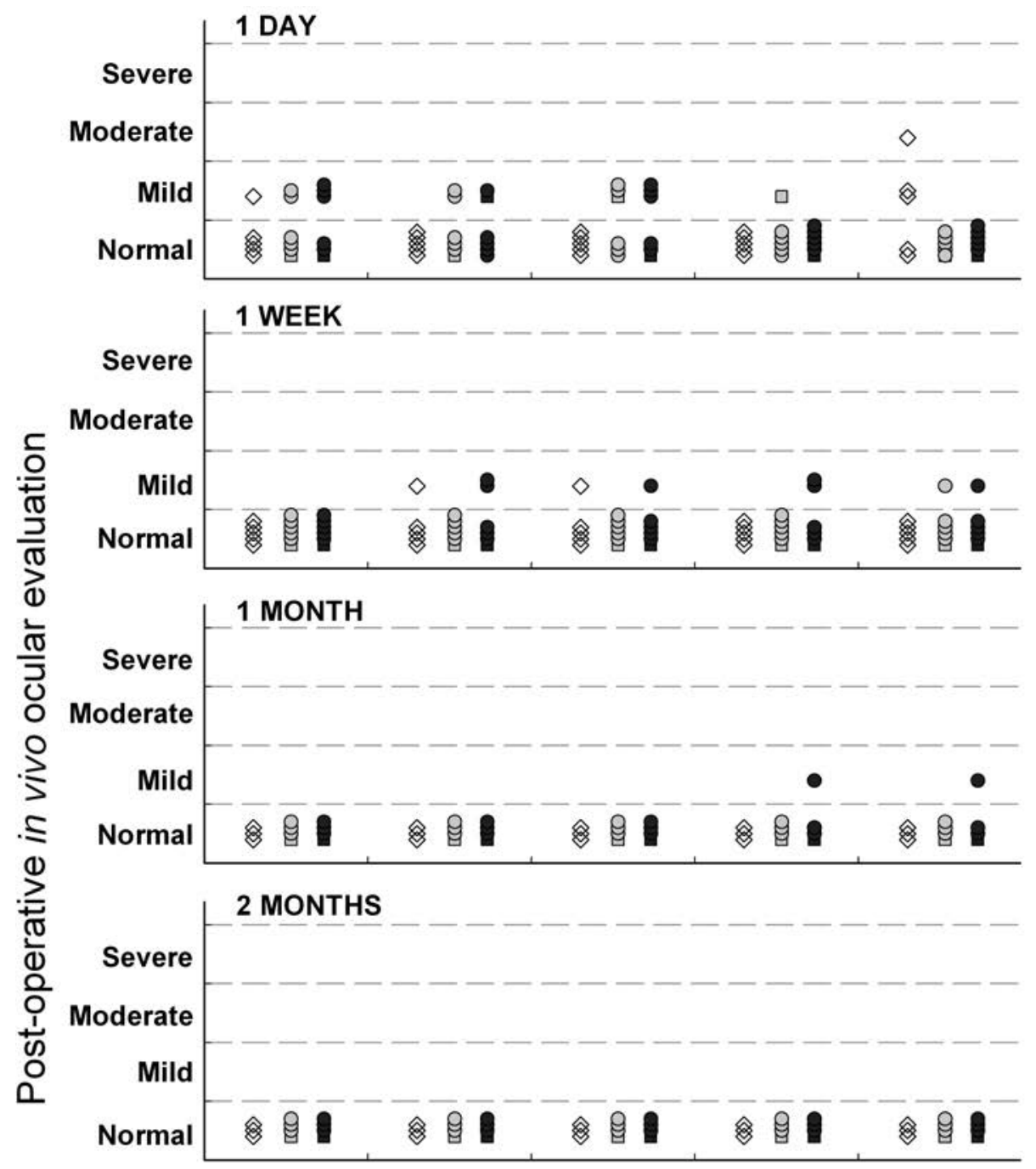

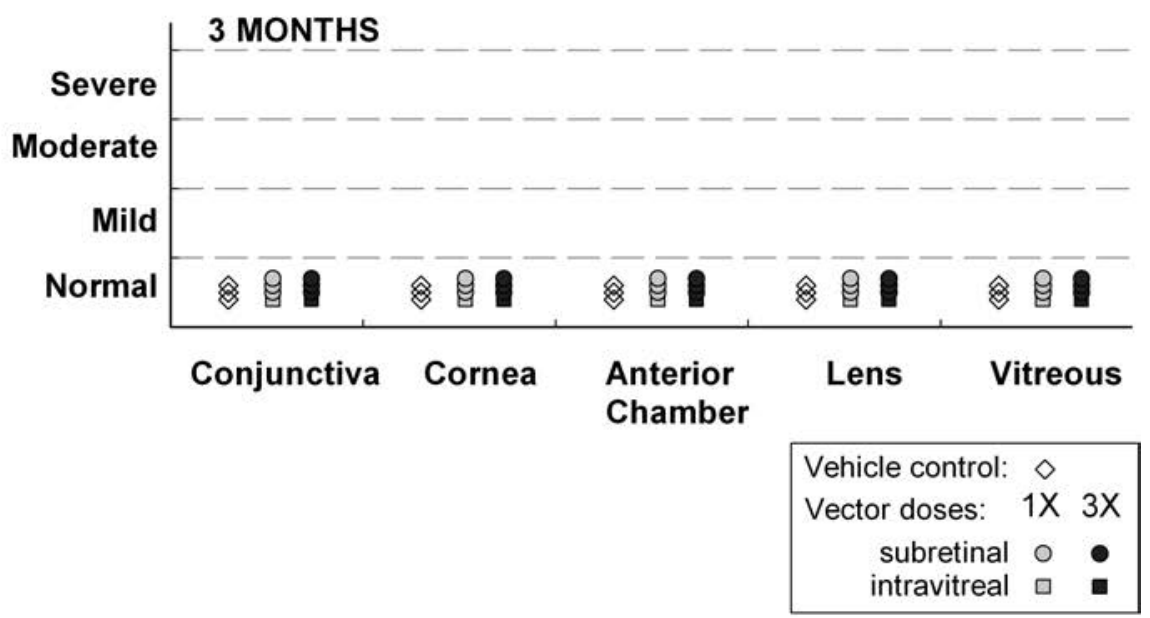

FIG. 2. Ocular examination results at five time points spanning 3 months in monkeys after delivery of rAAV-2/2.RPE65 (circles and squares) compared with vehicle control (open diamonds). Inflammatory changes (conjunctival hyperemia, chemosis, or discharge; cellularity/precipitates in anterior chamber and/or vitreous) as well as changes in transparency of ocular media (cornea/lens/vitreous) were assessed by slit lamp biomicroscopy and indirect ophthalmoscopy. Clinical changes were graded at three levels of severity. Results from individual eyes are presented from left to right in order of increasing relative vector dose levels; data points are arbitrarily offset in the vertical direction within each dose level and ocular evaluation category. The two vector doses are represented by gray $(1 \times)$ and black $(3 \times)$ in the symbols (scale at bottom right). 
resentative waveforms using four stimulus conditions in monkey 14 (M14) (subretinal, $3 \times$ dose in RE) illustrate that there were no dramatic interocular differences (IODs) posttreatment (Fig. 3B), compared with the pretreatment recordings (Fig. 3A). By inspection, the results in all 11 monkeys showed no dramatic IOD. Quantitative comparisons of intervisit variation and IODs for five amplitude parameters are also provided (Fig. 3C). Treated eyes (REs) and untreated eyes (LEs) showed similar intervisit variation for all measured parameters; there were no statistically significant differences between eyes for the parameters tested, regardless of vector dose ( $p>0.5$ for all comparisons). The standard deviations for intervisit differences (posttreatment minus pretreatment) in amplitude parameters (in microvolts) for untreated eyes were as follows: rod b-wave, 22.2; mixed a-wave, 23.5; mixed b-wave, 41.5; cone single-flash b-wave, 21.5; and cone flicker, 25.6. For IOD, we found no significant difference ( $p>0.6$ for all comparisons) when measured at pre- or posttreatment sessions. This was true for all vector-treated eyes. The standard deviations for IOD in amplitude parameters (in microvolts) for pretreatment recordings were as follows: rod, 17.2; mixed a-wave, 17.2; mixed b-wave, 24.4; cone singleflash b-wave, 8.5; and cone flicker, 8.7.

\section{Anti-AAV2 antibody assays}

Circulating antibodies to AAV2 capsid proteins were assayed by ELISA from collected serum samples. In the 1-week study, serum samples were assayed from days 0,2 , and 8 postinjection. Antibody titers were calculated relative to serial dilution of a positive anti-AAV2 human serum run simultaneously. For all animals, the antibody titers were low before treatment (range, $5.7-53.7 \mathrm{mU} / \mathrm{ml}$ ) and remained so for the study duration. In the 3-month study, serum samples were assayed from days $0,8,30$, and 90 postinjection. Although pretreatment levels ranged from 3471 to $406,556 \mathrm{mU} / \mathrm{ml}$, suggesting many animals had substantial preexisting anti-AAV2 antibodies, there was no consistent increase or decrease over the 3-month period after vector administration as a function of either vector dose or site of injection.

\section{Pathology and vector biodistribution: study I}

Necropsy and non-ocular histopathology. There were no gross necropsy findings noted at termination of the study. There were no test article-related changes in organ weights. Microscopy showed minimal chronic inflammation of the heart in five of six monkeys, including M1 (SR vehicle control injection); the exception was M2, the other SR vehicle-injected monkey. No microscopic lesions were considered to be related to administration of the test article; and all microscopic findings were interpreted as incidental findings commonly present in nonhuman primate toxicology studies.

Ocular histopathology. Anterior segments of all eyes were abnormal because of postmortem processing (bisection of eyes) in order to share tissue for histology and biodistribution studies. The optic nerves had no lesions except in the RE of M1 and M2 (both vehicle controls), in which there were subtle vacuoles containing macrophages.
FIG. 3. Retinal function before and after unilateral (RE) subretinal injections in monkeys. Representative ERG tracings (M14) before (A) and 3 months after (B) RE subretinal injection of the vector. Dark-adapted rod and mixed cone-rod ERGs, and light-adapted cone ERGs to 1- and 29-Hz flicker are shown. Stimulus onset is at trace onset or denoted by vertical gray bars in 29$\mathrm{Hz}$ responses. Calibration bars are at bottom right of waveforms. (C) Comparison of ERG amplitudes between treated eyes (diamonds, vehicle control; circles, two different doses of rAAV2/2.RPE65) and untreated eyes (squares). First row: intervisit differences (posttreatment minus pretreatment) in treated and untreated eyes. Dashed lines represent means $\pm 2 \mathrm{SD}$ of the intervisit differences for the untreated eyes; dotted line indicates zero. Second row: interocular differences (RE minus LE) measured at pre- and posttreatment sessions. Dashed lines represent means \pm 2 SD of the interocular differences pretreatment; dotted line indicates zero difference.

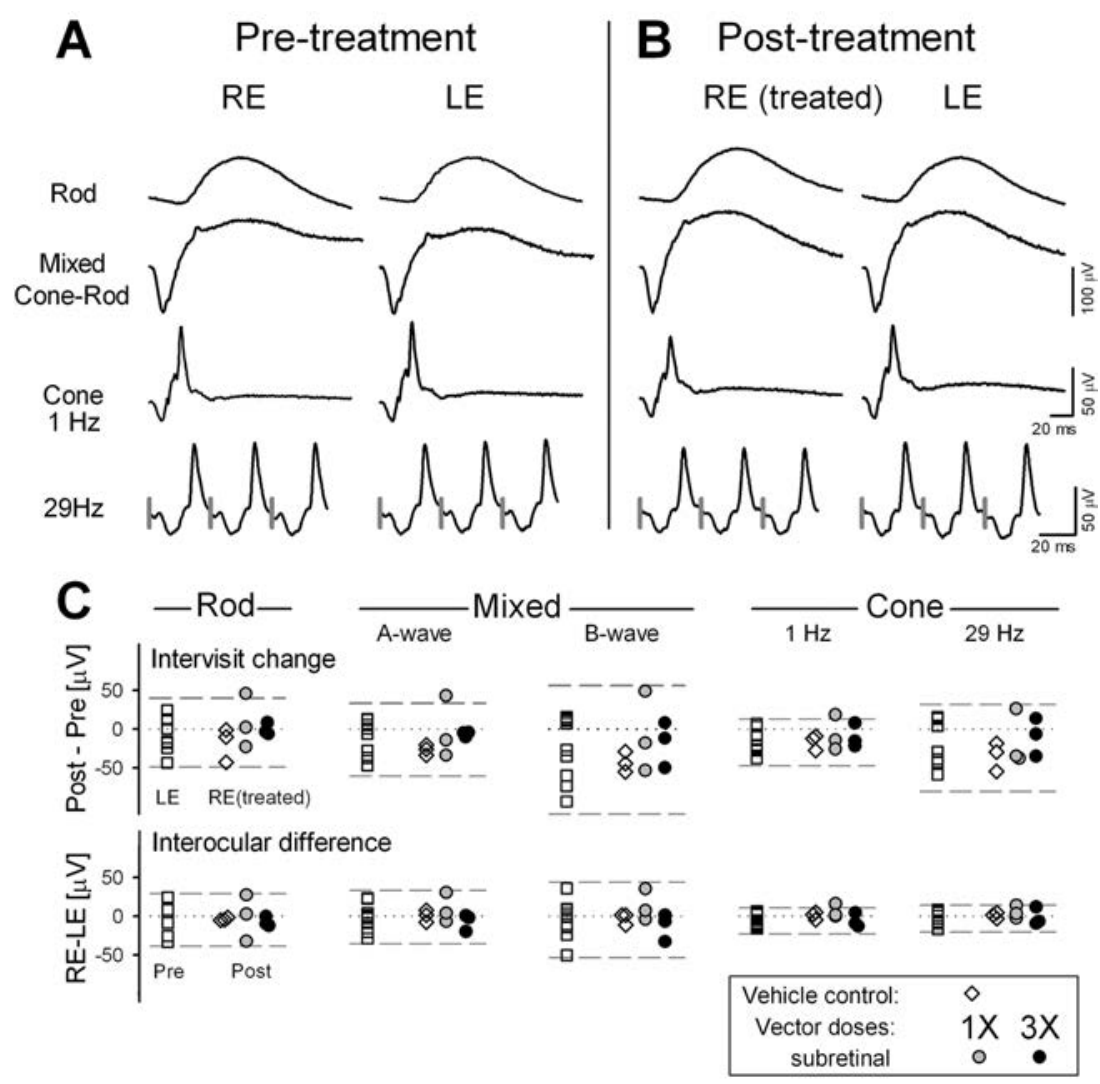


Retinal sections were taken vertically through the temporal retinal region of subretinally injected REs and in a comparable location in the LEs. A nasal retinal section was also taken from each eye. There was no evidence of necrosis, inflammation, cell proliferation, or extensive hemorrhage in any of the eyes. Pathological changes were definitely present in the REs of all six animals. Retinal perforation with detachment, presumably from the subretinal injection, was identified in the superior posterior temporal retina of the RE of all animals. These detachments were accompanied by clusters of glial cells, melanophages, and retinal pigment epithelium (RPE) cells. In addition, nuclear fragments of dying photoreceptor cells appeared to be present. The inferior temporal retina and nasal retina had no perforation sites, as anticipated from fundus drawings of the site of injection (Fig. 1), but artifactual detachment due to postmortem processing was present in most sections.

Biodistribution. Vector biodistribution was studied in ocular tissues and other organs of six monkeys (Table 2). Vector DNA was detectable in two different non-ocular, non-CNS tissues at

Table 2. Detection of raAV Vector Sequences by PCR in Nonhuman

Primate Tissue Samples: Study I, One-Week Duration

\begin{tabular}{|c|c|c|c|c|c|c|}
\hline & $\begin{array}{c}M 1^{\mathrm{a}} \\
O^{\mathrm{b}} / S R^{\mathrm{c}}\end{array}$ & $\begin{array}{c}M 2 \\
O / S R\end{array}$ & $\begin{array}{c}M 3 \\
1 \times / S R\end{array}$ & $\begin{array}{c}M 4 \\
1 \times / S R\end{array}$ & $\begin{array}{c}M 5 \\
3 \times / S R\end{array}$ & $\begin{array}{c}M 6 \\
3 \times / S R\end{array}$ \\
\hline \multicolumn{7}{|l|}{ Non-ocular tissues } \\
\hline Heart & - & - & na & - & - & - \\
\hline Lung & na & na & na & na & na & - \\
\hline Liver & - & - & - & na & - & - \\
\hline Pancreas & - & - & - & - & - & - \\
\hline Spleen & na & na & - & - & - & - \\
\hline Kidney & - & na & na & - & na & - \\
\hline Jejunum & - & - & na & - & - & - \\
\hline Gonads & - & - & - & - & - & - \\
\hline Skeletal muscle & - & - & $+(152)$ & $+(3,781)$ & - & - \\
\hline \multicolumn{7}{|l|}{ Lymph nodes } \\
\hline Preauricular & - & na & - & $\pm(180)$ & - & na \\
\hline Mandibular & - & - & na & - & - & - \\
\hline Tracheobronchial & - & - & - & - & - & - \\
\hline Mesenteric & na & na & na & - & - & - \\
\hline \multicolumn{7}{|l|}{ Eye and orbit (L) } \\
\hline Vitreous (L) & nd & - & na & - & nd & nd \\
\hline Retina (L) & - & - & - & - & - & - \\
\hline Optic nerve (L) & - & na & na & - & - & na \\
\hline Orbital tissue (L) & na & - & na & - & na & na \\
\hline \multicolumn{7}{|l|}{ Eye and orbit (R) } \\
\hline Vitreous (R) & - & na & $+(6,545)$ & $+(25,565)$ & $+(920,700)$ & nd \\
\hline Retina $(\mathrm{R})$ & - & - & $+(2,930,674)$ & $+(436,307)$ & $+(470,375)$ & $+(2,459,501)$ \\
\hline Optic nerve (R) & na & - & $+(601)$ & $+(127)$ & $+(1,360)$ & $+(665)$ \\
\hline Orbital tissue (R) & - & - & na & - & - & na \\
\hline Optic chiasm & - & - & - & - & - & - \\
\hline \multicolumn{7}{|l|}{ Visual pathways (L brain) } \\
\hline Optic tract $(\mathrm{L})$ & - & $+(124)$ & - & $+(439)$ & $\pm(106)$ & - \\
\hline LGN (L) & - & - & - & - & - & - \\
\hline Visual cortex (L) & - & - & - & - & $+(200)$ & - \\
\hline Superior colliculus (L) & - & - & - & - & - & $+(184)$ \\
\hline \multicolumn{7}{|l|}{ Visual pathways ( $\mathrm{R}$ brain) } \\
\hline Optic tract $(\mathrm{R})$ & - & na & - & $\pm(155)$ & $+(114)$ & $+(264)$ \\
\hline LGN (R) & - & - & - & $\pm(144)$ & $\pm(123)$ & - \\
\hline Visual cortex $(\mathrm{R})$ & - & na & - & - & - & - \\
\hline Superior colliculus (R) & na & na & - & - & - & - \\
\hline \multicolumn{7}{|l|}{ Brain samples (other) } \\
\hline Thalamus (L) & - & - & - & - & - & - \\
\hline Thalamus (R) & - & - & na & - & - & - \\
\hline Cerebellum & - & - & na & - & na & na \\
\hline
\end{tabular}

Abbreviations: L, left; R, right; - , no PCR amplification; PCR amplification of vector sequences: + (replicated value shown is average, copy number per microgram of genomic DNA); \pm (single replicate value only, copy number per microgram of genomic DNA); na, not available (not determinable because of an unacceptable spike-in); nd, not done; LGN, lateral geniculate nucleus.

aAnimal no.

bVector dose, relative per Table 1.

${ }^{\mathrm{c}}$ Route of ocular delivery, subretinal (SR). 
$\geq 100$ single-stranded DNA copies per microgram of genomic DNA. M3 and M4, the two monkeys with subretinal $1 \times$ dose, both showed positive and replicated results for the skeletal muscle sample (thigh). M4 also had a single value (that did not replicate on retest) in the preauricular node sample. M5 and M6, representing higher doses, did not show vector sequences in these tissues, making the significance of the $1 \times$ dose results uncertain. All gonadal samples were negative for vector sequences. Both vector-dosed groups had positive and replicated results in the vector-injected RE: retina, vitreous, and optic nerve. The uninjected LE tissues were negative for vector sequences, as were both LE and RE orbital tissue samples. The optic chiasm was negative in all vector-dosed animals. Of the 32 further samples from the visual pathways in vector-dosed monkeys, there were 5 positive and replicated results and 4 results with vector sequences in only one of the two replicate PCR determinations (Table 2). Most of these positive results in the visual pathways of these monkeys were just above the 100-copy minimum reportable value. M3, an animal with a $1 \times$ dose, had no vector sequences in the visual brain. Other brain samples (thalamus and cerebellum) were negative in all monkeys. The results suggest that 1 week after subretinal vector delivery, there is only sporadic and limited vector DNA detectable outside of the injected eye and optic nerve.

\section{Pathology and vector biodistribution: study II}

Necropsy and non-ocular histopathology. No gross necropsy findings were noted at termination of the study. There were no test article-related changes in organ weights. Mild chronic inflammation of the heart was noted in M15, the only female monkey that received a subretinal $3 \times$ vector dose. The only female vehicle control (M9) did not show this result. There was also a low level of chronic inflammation of the kidneys in some of the monkeys, but this level is commonly present in primate kidneys and not considered vector dose related (Roberts et al., 1972; Skelton-Stroud and Glaister, 1987).

Ocular histopathology. Retinotomy sites were identified in the superior central retina of most eyes with subretinal injections. These retinal perforations appeared to be healed with no signs of inflammation. Superior retinal sections from two eyes with subretinally injected vehicle (M7 and M8) and two eyes with vector injections (M15 and M13) are illustrated in Fig. 4. M7 has a healed needle track with disruption of the inner nuclear layer (INL) and focal loss of ganglion cells (Fig. 4A). M8, also with a healed needle track, has focal loss of photoreceptors and ganglion cells with mild disorganization of the inner nuclear layer (Fig. 4B). M15 ( $3 \times$ vector-injected eye) has a healed needle track with disruption of retinal laminae and modest loss of cells of all layers (Fig. 4C). M13, another $3 \times$ vector-injected eye, has a healed retinal perforation site with all layers in register but there is focal RPE change, an ONL with variable thickness, and vacuolar spaces in the INL (Fig. 4D). The uninjected LEs of all animals showed no such retinal lesions. There were no lesions in the optic nerves.

Most central retinal sections were through the fovea and many were near the foveola (Polyak, 1941; Hogan et al., 1971; Provis et al., 2005). Foveal anatomy in most of the eyes with subretinal injections was locally abnormal. Of the three eyes with vehicle injections, M9 showed some pigment in the subretinal space of the RE (Fig. 4E) that was not evident in the uninjected LE (Fig. 4F). Two of three eyes with the $1 \times$ vector dose also had subretinal or intraretinal pigmentary disturbances at the fovea. The most extreme change was in the RE of M10 (Fig. 4G): there was a foveal retinal detachment of about $1 \mathrm{~mm}$ in diameter and thick subretinal tissue composed of fibroblasts, melanocytes, and possibly RPE cells; both eyes from this animal shared artifactual fragmentation of the inner retina (Fig. 4G and $\mathrm{H}$ ). A small clump of pigment was also present within the foveal ONL of the RE of M11. The other animal with $1 \times$ subretinal injection, M12, showed no such abnormalities in the fovea of the RE. Two of three animals with a $3 \times$ vector dose injected subretinally had no obvious differences between the foveal regions of injected and uninjected eyes. ONL and photoreceptor outer segments adjacent to the fovea of the RE of M14 (Fig. 4I), however, appeared slightly thinner than those of the LE (Fig. 4J). Such impressions prompted morphometry of the ONL (see below). Of the two eyes with intravitreal injections, one had no foveal section available (M16, RE); a section from the RE of M17 was normal-appearing and not obviously different from the LE.

Thickness of the ONL was sampled at 2, 4, 6, and $10 \mathrm{~mm}$ eccentric from the central fovea in the superior and inferior retina of the RE of the nine monkeys with subretinal injections and in one of two intravitreally injected monkeys (Fig. 5A). Similar analyses were performed in the temporal retina (Fig. 5B) and nasal retina (Fig. 5C). The uninjected LE of eight of nine monkeys with RE subretinal injections (M7, LE section was unavailable) and the uninjected LE of both intravitreally injected animals served as controls for these ONL measurements. Only the injected eyes of M10 ( $1 \times$ dose) and M14 ( $3 \times$ dose) were reduced in ONL thickness compared with control eyes. Both M10 and M14 fell outside the normal limits (defined as $2 \mathrm{SD}$ from mean of LE data) at $2 \mathrm{~mm}$ in the central superior retina; M10 was also abnormally reduced at $4 \mathrm{~mm}$ superiorly. These superior retinal locations were within the injection region. Using a criterion of $3 \mathrm{SD}$, however, all loci were within normal limits. Other eyes with $1 \times$ and $3 \times$ doses were within the normal limits (Fig. 5A). Temporal retinal ONL thickness measurements were measured and plotted (Fig. 5B); at the 10-mm superior eccentric locus, M9 (vehicle control injection) showed an abnormally thinned ONL. Nasal retinal measurements in the vertical meridian (nasal to the optic nerve) showed no ONL thinning in any of the injected eyes.

Immunocytochemical staining of vertical sections through the central retina showed RPE65 localization only within the $\mathrm{RPE}$, as expected in these normal animals. Intensity of the RPE65 label was comparable between all positive slides. Background/nonspecific labeling was low and negative controls provided conclusive determination that there was no labeling outside the RPE in any of the positive slides.

Biodistribution. Vector biodistribution 3 months after ocular injection was studied in non-ocular tissues as well as in orbital tissue, optic nerve, and visual pathways of the 11 monkeys (Table 3). Unlike in the 1-week study, the eyes were analyzed exclusively for histopathology (see Materials and Methods, above). Of the non-ocular tissues, a single positive and replicated result was found in the lung sample of M16 (1×, intra- 

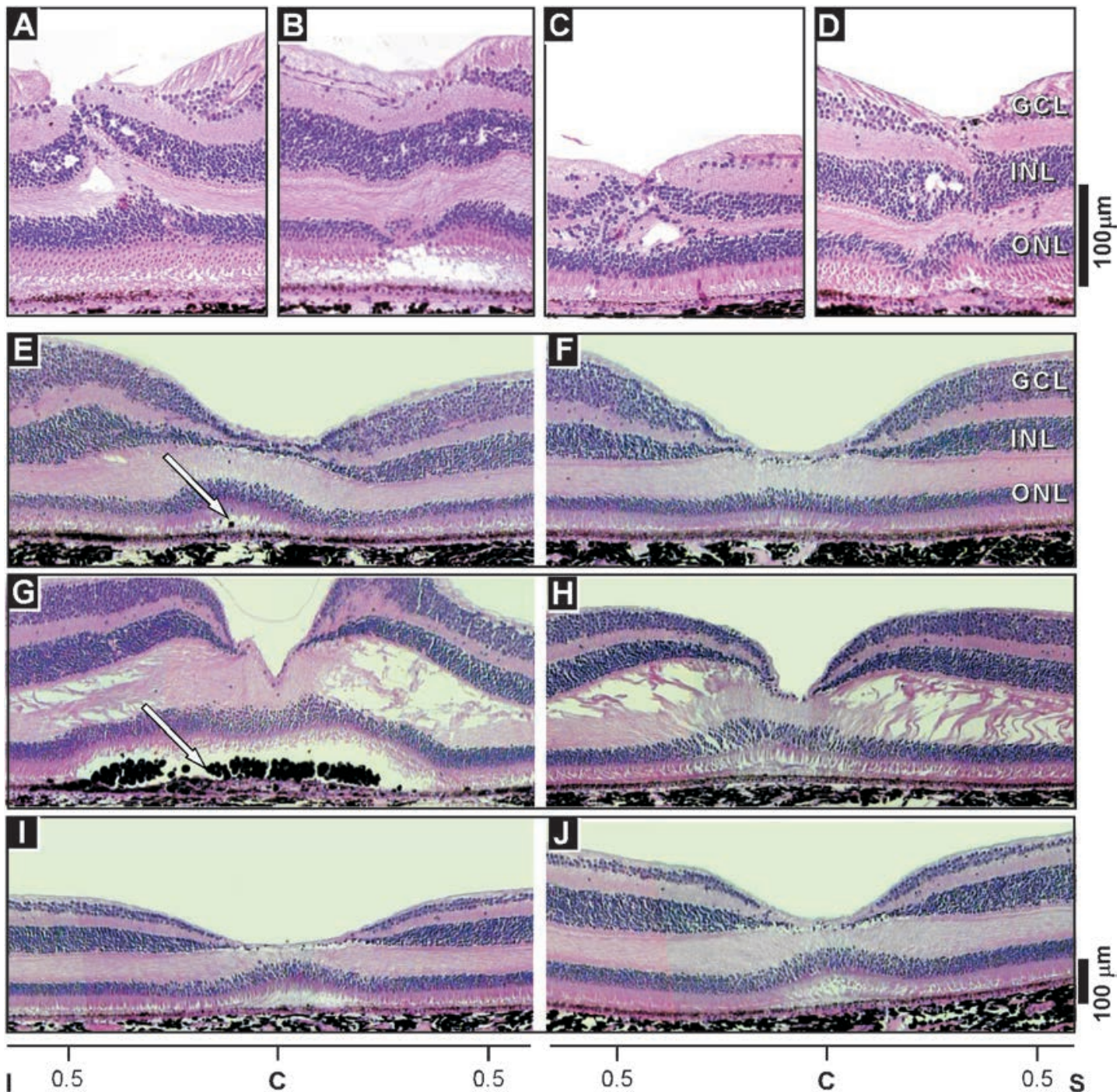

Retinal Distance [mm]

FIG. 4. Ocular histopathology of monkeys 3 months postinjection of rAAV-2/2.RPE65 vector or vehicle. (A-D) Superior central retinal locations (subretinal injection site) in the RE of four monkeys. (A and B) Two monkeys (M7 and M8) with vehicle injections. (C and D) Two monkeys (M15 and M13) with $3 \times$ vector injections. (E-J) Foveal histopathology in the RE and LE of three monkeys. REs are depicted on the left; LEs are on the right. (E and F) M9, a vehicle-injected animal, shows subretinal pigment (arrow) in the injected RE but not in the LE. (G and H) M10, a $1 \times$ vector-injected animal, shows thick pigmented subretinal tissue (arrow) in the injected RE but not in the LE. There is artifactual inner retinal fragmentation in both eyes. (I and $\mathbf{J}$ ) M14, a $3 \times$ vector-injected animal, shows normal foveal architecture in both eyes but slightly thinner outer retinal layers in the RE. GCL, ganglion cell layer; INL, inner nuclear layer; ONL, outer nuclear layer.

vitreal). Otherwise, no vector sequences were detected in nonocular tissues or in the orbital samples. All optic nerves from vector-dosed eyes were negative, as was the optic chiasm from these animals. Of the 10 samples from the visual pathways of each of the 9 vector-dosed monkeys, only 1 positive result (replicated) was found and this was in the left lateral geniculate nucleus of M11 ( $1 \times$, subretinal). All gonadal tissue was negative. The results suggest that 3 months after subretinal and intravitreal vector delivery, vector DNA is not widely detectable in non-ocular tissues, including gonads, or in the optic nerve and other parts of the visual pathways sampled.

\section{DISCUSSION}

Gene therapy using recombinant AAV2 is attractive because of efficient and prolonged transgene expression in target tissues (reviewed in Couto, 2004; Flotte, 2005). Preclinical intraocular gene transfer experiments using rAAV2 have increased in number and there are many successes in animal models of otherwise incurable human retinal diseases (Surace and Auricchio, 2003; Rolling, 2004; Auricchio and Rolling, 2005; Dinculescu et al., 2005). The next step toward human application of rAAV2-mediated gene transfer to the retina requires safety data. 

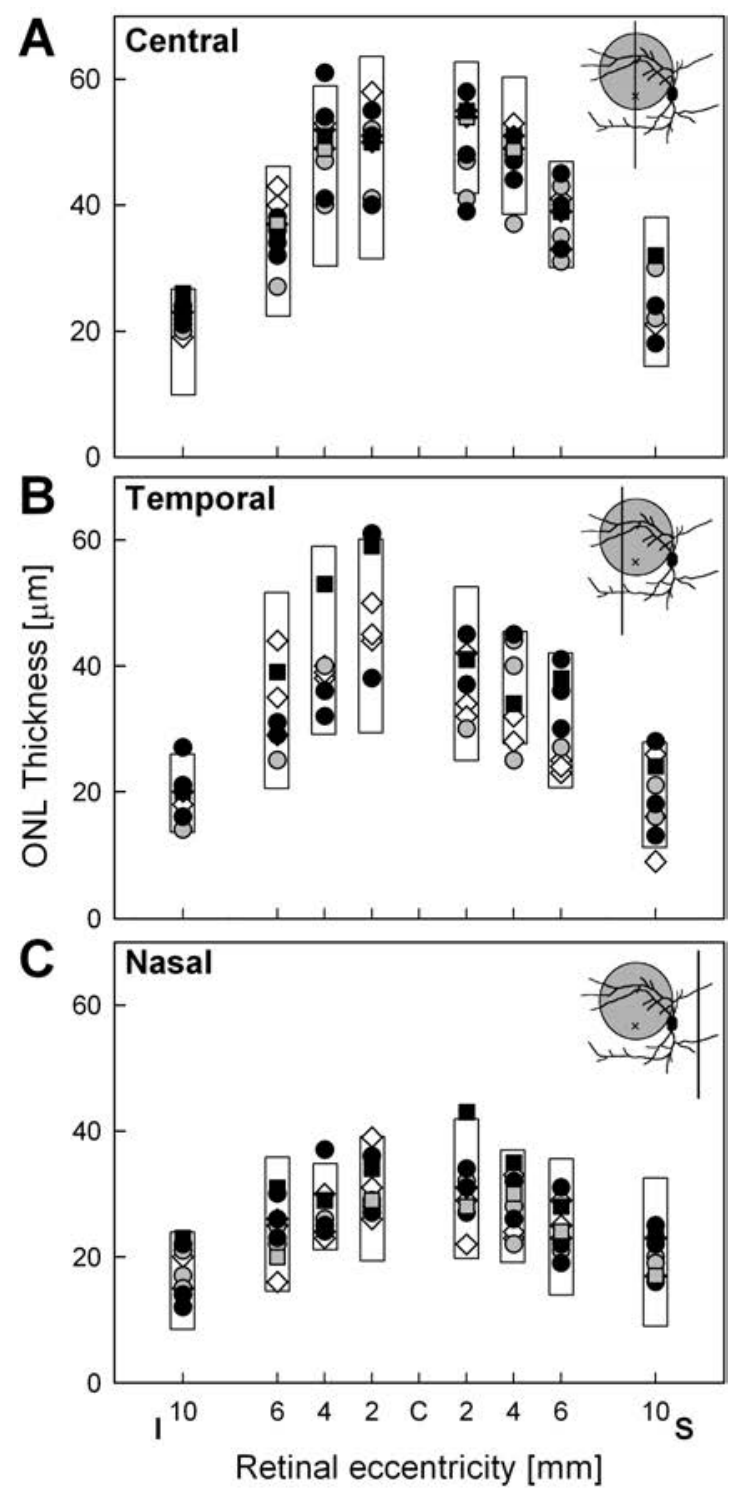

Vehicle control: $\diamond$
Vector doses: $1 \times 3 \times$
subretinal $\bigcirc$

FIG. 5. Retinal morphometry of monkeys at 3 months postinjection of rAAV-2/2.RPE65 vector. Measurements are of the outer (photoreceptor) nuclear layer thickness at three locations: through the fovea $(\mathbf{A})$, in the temporal retina $(\mathbf{B})$, and in the nasal retina $(\mathbf{C})$. Shaded circles are the approximate area covered by the subretinal injection. Circles, eyes with subretinal injections; squares, intravitreal injections (the two different doses of rAAV-2/2.RPE65 are depicted as gray, $1 \times$, or black, $3 \times)$; diamonds, control eyes with subretinal vehicle-only injections. I, inferior; $S$, superior retina; $C$, center (level of the fovea). Bars represent means \pm 2 SD limits for measurements made at corresponding locations on the control (LE) eyes.

We performed a series of dose-efficacy and safety experiments in dogs and rats for rAAV-2/2.RPE65 (Jacobson et al., 2006) as a step toward a human trial of gene transfer in patients with blindness caused by mutations in the RPE65 gene (Jacobson et al., 2005). The results in the RPE65-mutant dog showed a range of efficacious doses, but retinal histopathology at the highest two doses used suggested modest toxicity in some of the animals. The current study in the normal nonhuman primate was undertaken to seek further data on systemic and local ocular effects of these higher vector doses to define the upper dose limit in future human trials.

No systemic toxicity was detected in the monkeys after either dose of ocular rAAV-2/2.RPE65. Dissemination of vector to organs distal to the eye after intraocular delivery has now been investigated in three species using rAAV-2/2.RPE65. Our biodistribution studies in normal rats at approximately 2 weeks and 2 months after subretinal or intravitreal gene transfer indicated that vector spread outside the treated eye was limited (Jacobson et al., 2006). RPE65-mutant dogs studied 3 months after subretinal delivery showed only sporadic vector sequences in distal organs and no consistent pattern of dissemination. One dog had detectable vector sequences in one optic nerve (after bilateral injections) and another had vector in the chiasm; the levels were near the detection limit and were not found on repeat testing. Among the five dogs tested for vector sequences in the visual pathways distal to the chiasm, there were no positive results. The present study in nonhuman primates under GLP conditions extends these observations with short-term and 3-month vector biodistribution data at the two highest doses used in the dog studies. By 1 week after subretinal injection, there are high levels of detectable vector sequences in the retina and also in the vitreous, with lesser levels in the intraorbital optic nerve. Distal to the optic nerve, there was only isolated detection of vector sequences (mainly near the limit of detection) and these were not apparently related to vector dose or vector level in the retina. Non-ocular dissemination was not observed. The longer term study of 3 months was almost devoid of detectable vector sequences in both non-ocular distal tissues and the visual pathways whether the vector administration was subretinal or intravitreal. Pertinent to concerns about germ line transmission, based on previous studies of AAV2 (reviewed in Couto, 2004), vector genomes were not detected in the gonads of female or male vector-treated animals, indicating that in a nonhuman primate and at the doses used in this study, the risk is minimal. There are no other published studies of nonhuman primates with ocular injections specifically of rAAV-2/2. RPE65. Two macaques (Macaca fascicularis) with subretinal rAAV-2/4.CMV.gfp were studied for biodistribution; one was killed 2 months postinjection and the other was biopsied (Provost et al., 2005). Vector sequences were detected in the injected retina and optic nerve, as in our shorter term study. The conclusion from the available biodistribution data is that subretinal delivery of AAV-2/2.RPE65 does not lead to widespread dissemination of vector DNA in a dose-dependent manner. The no-observed adverse event level is $4.5 \times 10^{12} \mathrm{vg}$.

Retinal toxicity was assayed by clinical eye examinations, ERG, and retinal histopathology with morphometry. There was no evidence for toxicity beyond the effects expected from the retinal surgical procedure. The histopathological data in the nonhuman primate retina after subretinal injection challenges our conclusion from the RPE65-mutant dog that higher doses of subretinal rAAV-2/2.RPE65 may be threatening to retinal integrity. This may permit consideration of dose escalation in humans to at least $1.5 \times 10^{12} \mathrm{vg}$. The literature describes subretinal delivery of rAAV-2/4.CMV.gfp in one macaque ( $M$. 
Table 3. Detection of raAV Vector Sequences by PCR in Nonhuman Primate Tissue Samples: Study II, 3-MONTh DuRation

\begin{tabular}{|c|c|c|c|c|c|c|c|c|c|c|c|}
\hline & $\begin{array}{c}M 7^{\mathrm{a}} \\
O^{\mathrm{b}} / S R^{\mathrm{c}}\end{array}$ & $\begin{array}{c}M 8 \\
O / S R\end{array}$ & $\begin{array}{c}M 9 \\
O / S R\end{array}$ & $\begin{array}{c}M 10 \\
1 \times / S R\end{array}$ & $\begin{array}{c}M 11 \\
1 \times / S R\end{array}$ & $\begin{array}{c}M 12 \\
1 \times / S R\end{array}$ & $\begin{array}{c}M 13 \\
3 \times / S R\end{array}$ & $\begin{array}{c}M 14 \\
3 \times / S R\end{array}$ & $\begin{array}{c}M 15 \\
3 \times / S R\end{array}$ & $\begin{array}{l}M 16 \\
I \times / I V\end{array}$ & $\begin{array}{c}M 17 \\
3 \times / I V\end{array}$ \\
\hline \multicolumn{12}{|l|}{ Non-ocular tissues } \\
\hline Heart & - & - & - & - & - & - & - & - & - & - & - \\
\hline Lung & nd & nd & - & - & - & - & - & - & - & $+(534)$ & - \\
\hline Liver & - & - & - & - & - & - & - & - & - & - & - \\
\hline Pancreas & - & - & - & - & - & - & - & - & - & - & - \\
\hline Spleen & - & - & - & - & - & - & - & - & - & - & - \\
\hline Kidney & - & - & - & - & - & - & - & - & - & - & - \\
\hline Jejunum & - & - & - & - & - & - & - & - & - & - & - \\
\hline Gonads & - & - & - & - & - & - & - & nd & - & - & - \\
\hline Skeletal muscle & - & - & - & - & - & - & - & - & - & - & - \\
\hline \multicolumn{12}{|l|}{ Lymph nodes } \\
\hline Preauricular & - & - & - & - & - & - & - & - & - & - & - \\
\hline Mandibular & - & - & - & - & - & - & - & - & - & - & - \\
\hline Tracheobronchial & - & nd & - & - & - & - & - & - & - & - & - \\
\hline Mesenteric & - & - & - & - & - & - & - & - & - & - & - \\
\hline \multicolumn{12}{|l|}{ Eye and orbit (L) } \\
\hline Optic nerve (L) & - & - & - & - & - & - & - & - & - & - & - \\
\hline Orbital tissue (L) & - & - & - & - & - & - & - & - & - & - & - \\
\hline \multicolumn{12}{|l|}{ Eye and orbit $(\mathrm{R})$} \\
\hline Optic nerve (R) & - & - & - & - & - & - & - & - & - & - & - \\
\hline Orbital tissue (R) & - & - & - & - & - & - & - & - & - & - & - \\
\hline Optic chiasm & - & - & - & - & - & - & - & - & - & - & - \\
\hline \multicolumn{12}{|l|}{ Visual pathways (L brain) } \\
\hline Optic tract $(\mathrm{L})$ & - & - & - & - & - & - & - & - & - & - & - \\
\hline LGN (L) & - & - & - & - & $+(126)$ & - & - & - & - & - & - \\
\hline Optic radiation $(\mathrm{L})$ & - & - & - & - & - & - & - & - & - & - & - \\
\hline Visual cortex $(\mathrm{L})$ & - & - & - & - & - & - & - & - & - & - & - \\
\hline Superior colliculus (L) & - & - & - & - & - & - & - & - & - & - & - \\
\hline \multicolumn{12}{|l|}{ Visual pathways ( $\mathrm{R}$ brain) } \\
\hline Optic tract $(\mathrm{R})$ & - & - & - & - & - & - & - & nd & - & - & - \\
\hline LGN (R) & - & - & - & - & - & - & - & - & - & - & - \\
\hline Optic radiation $(\mathrm{R})$ & - & - & - & - & - & - & - & - & - & - & - \\
\hline Visual cortex $(\mathrm{R})$ & - & - & - & - & - & - & - & - & - & - & - \\
\hline Superior colliculus (R) & - & - & - & - & - & - & - & - & - & - & - \\
\hline \multicolumn{12}{|l|}{ Brain samples (other) } \\
\hline Thalamus (L) & - & - & - & - & - & - & - & - & - & - & - \\
\hline Thalamus (R) & - & - & - & - & - & - & - & - & - & - & - \\
\hline Cerebellum & - & - & - & - & - & - & - & - & - & - & - \\
\hline
\end{tabular}

Abbreviations: L, left; R, right; - , no PCR amplification; PCR amplification of vector sequences: + (replicated value shown is average, copy number per microgram of genomic DNA); \pm (single replicate value only, copy number per microgram of genomic DNA); na, not available (not determinable because of an unacceptable spike-in); nd, not done; LGN, lateral geniculate nucleus.

${ }^{\mathrm{a} A n i m a l}$ no.

${ }^{b}$ Vector dose, relative per Table 1 .

${ }^{\mathrm{c}}$ Route of ocular delivery: subretinal (SR), intravitreal (IV).

fascicularis) and this experiment indicated long-term (18 months) transgene expression and no obvious interocular difference in ERGs between treated and untreated eyes. Clinical eye examinations performed in other monkeys at shorter intervals after such subretinal injections showed transgene expression but no ocular inflammation; ocular histopathology was not reported (Le Meur et al., 2005).

Foveal analyses with in vivo microscopy in human LCA patients with RPE65 mutations showed disproportionately greater photoreceptor layer thickness than cone photoreceptor function, a finding consistent with the visual cycle abnormality in this disease (Jacobson et al., 2005). Theoretically, even in late stages of the disease, patients with measurable foveal structure could benefit from gene transfer, even if targeted exclusively to this retinal region. Experience with other retinal degenerative diseases that lead to loss of peripheral and rod photoreceptor-mediated vision, such as forms of retinitis pigmentosa (Kennan et $a l ., 2005)$, indicates that even a small island of retained conemediated vision can allow patients to maintain more independence and quality of life than without this function (Szlyk et 
al., 1998). The results of the present study suggest that the procedure to deliver genetic material to the central retina may be worth advancing, so as to decrease the chance of foveal injury by retinal detachment and not compromise the potentially positive effects of treatment. A nontraumatic method should be sought to deliver genetic material to the fovea, which is anatomically specialized with far less thickness and less cellular elements than surrounding retina and no retinal blood supply (Provis et al., 2005).

\section{ACKNOWLEDGMENTS}

The authors thank Jane Bauman, Elizabeth Windsor, Elaine Smilko, Paul Schied, Jill Fogleman, Thomas Ferrell, Philip Cross, Amy Poirier, Lynn Combee, Kirsten Erger, Cheryl Roberts, Arun Mani, Cathy Hoover, and Margaret Humphries for interaction over many aspects of this study. This work was supported by the NIH/NEI (EY-13729, EY-13385, EY-11123, EY-08571, EY-06855, EY-13132, and EY-08061), the Macula Vision Research Foundation, the Foundation Fighting Blindness, the Macular Disease Foundation, the Alcon Research Institute, ONCE International Prize for Biomedicine and R\&D for New Technologies for the Blind, Mackall Trust, and the F.M. Kirby Foundation.

\section{REFERENCES}

ACLAND, G.M., AGUIRRE, G.D., RAY, J., ZHANG, Q., ALEMAN, T.S., CIDECIYAN, A.V., PEARCE-KELLING, S.E., ANAND, V., ZENG, Y., MAGUIRE, A.M., JACOBSON, S.G., HAUSWIRTH, W.W., and BENNETT, J. (2001). Gene therapy restores vision in a canine model of childhood blindness. Nat. Genet. 28, 92-95.

ACLAND, G.M., AGUIRRE, G.D., BENNETT, J., ALEMAN, T.S., CIDECIYAN, A.V., BENNICELLI, J., DEJNEKA, N.S., PEARCE-KELLING, S.E., MAGUIRE, A.M., PALCZEWSKI, K., HAUSWIRTH, W.W., and JACOBSON, S.G. (2005). Long-term restoration of rod and cone vision by single dose rAAV-mediated gene transfer to the retina in a canine model of childhood blindness. Mol. Ther. 12, 1072-1082.

AURICCHIO, A., and ROLLING, F. (2005). Adeno-associated viral vectors for retinal gene transfer and treatment of retinal diseases. Curr. Gene Ther. 5, 339-348.

BATTEN, M.L., IMANISHI, Y., TU, D.C., DOAN, T., ZHU, L., PANG, J., GLUSHAKOVA, L., MOISE, A.R., BAEHR, W., GELDER, R.N., HAUSWIRTH, W.W., RIEKE, F., and PALCZEWSKI, K. (2005). Pharmacological and rAAV gene therapy rescue of visual functions in a blind mouse model of Leber congenital amaurosis. PLoS Med. 2, e333.

BENNETT, J., MAGUIRE, A.M., CIDECIYAN, A.V., SCHNELL, M., GLOVER, E., ANAND, V., ALEMAN, T.S., CHIRMULE, N., GUPTA, A.R., HUANG, Y., GAO, G.P., NYBERG, W.C., TAZELAAR, J., HUGHES, J., WILSON, J.M., and JACOBSON, S.G. (1999). Stable transgene expression in rod photoreceptors after recombinant adeno-associated virus-mediated gene transfer to monkey retina. Proc. Natl. Acad. Sci. U.S.A. 96, 9920-9925.

COUTO, L.B. (2004). Preclinical gene therapy studies for hemophilia using adeno-associated virus (AAV) vectors. Semin. Thromb. Hemost. 30, 161-171.

CREMERS, F.P., VAN DEN HURK, J.A., and DEN HOLLANDER, A.I. (2002). Molecular genetics of Leber congenital amaurosis. Hum. Mol. Genet. 11, 1169-1176.
CURCIO, C.A., SLOAN, K.R., KALINA, R.E., and HENDRICKSON, A.E. (1990). Human photoreceptor topography. J. Comp. Neurol. 292, 497-523.

DEJNEKA, N.S., SURACE, E.M., ALEMAN, T.S., CIDECIYAN, A.V., LYUBARSKY, A., SAVCHENKO, A., REDMOND, T.M., TANG, W., WEI, Z., REX, T.S., GLOVER, E., MAGUIRE, A.M., PUGH, E.N., Jr., JACOBSON, S.G., and BENNETT, J. (2004). In utero gene therapy rescues vision in a murine model of congenital blindness. Mol. Ther. 9, 182-188.

DINCULESCU, A., GLUSHAKOVA, L., MIN, S.H., and HAUSWIRTH, W.W. (2005). Adeno-associated virus-vectored gene therapy for retinal disease. Hum. Gene Ther. 16, 649-663.

DONSANTE, A., VOGLER, C., MUZYCZKA, N., CRAWFORD, J.M., BARKER, J., FLOTTE, T., CAMPBELL-THOMPSON, M., DALY, T., and SANDS, M.S. (2001). Observed incidence of tumorigenesis in long-term rodent studies of rAAV vectors. Gene Ther. 8, 1343-1346.

FLOTTE, T.R. (2005). Adeno-associated virus-mediated gene transfer for lung diseases. Hum. Gene Ther. 16, 643-648.

HARE, W.A., WOLDEMUSSIE, E., WEINREB, R.N., TON, H., RUIZ, G., WIJONO, M., FELDMANN, B., ZANGWILL, L., and WHEELER, L. (2004). Efficacy and safety of memantine treatment for reduction of changes associated with experimental glaucoma in monkey. II. Structural measures. Invest. Ophthalmol. Vis. Sci. 45, 2640-2651.

HOGAN, M.J., ALVARADO, J.A., and WEDDELL, J.E. (1971). Histology of the Human Eye. (WB Saunders, Philadelphia, PA) pp. 393-522.

JACOBSON, S.G., YAGASAKI, K., FEUER, W.J., and ROMAN, A.J. (1989). Interocular asymmetry of visual function in heterozygotes of X-linked retinitis pigmentosa. Exp. Eye Res. 48, 679-691.

JACOBSON, S.G., MORALES, D.S., SUN, X.K., FEUER, W.J., CIDECIYAN, A.V., GASS, J.D., and MILAM, A.H. (1995). Pattern of retinal dysfunction in acute zonal occult outer retinopathy. Ophthalmology 102, 1187-1198.

JACOBSON, S.G., ALEMAN, T.S., CIDECIYAN, A.V., SUMAROKA, A., SCHWARTZ, S.B., WINDSOR, E.A., TRABOULSI, E.I., HEON, E., PITTLER, S.J., MILAM, A.H., MAGUIRE, A.M., PALCZEWSKI, K., STONE, E.M., and BENNETT, J. (2005). Identifying photoreceptors in blind eyes caused by RPE65 mutations: Prerequisite for human gene therapy success. Proc. Natl. Acad. Sci. U.S.A. 102, 6177-6182.

JACOBSON, S.G., ACLAND, G.M., AGUIRRE, G.D., ALEMAN, T.S., SCHWARTZ, S.B., CIDECIYAN, A.V., ZEISS, C.J., KOMAROMY, A.M., KAUSHAL, S., ROMAN, A.J., WINDSOR, E.A.M., SUMAROKA, A., PEARCE-KELLING, S.E., CONLON, T.J., CHIODO, V.A., BOYE, S.L., FLOTTE, T.R., MAGUIRE, A.M., BENNETT, J., and HAUSWIRTH, W.W. (2006). Safety of recombinant adeno-associated virus type 2$R P E 65$ vector delivered by ocular subretinal injection. Mol. Ther. 13, 1074-1084.

JIN, M., LI, S., MOGHRABI, W.N., SUN, H., and TRAVIS, G.H. (2005). Rpe65 is the retinoid isomerase in bovine retinal pigment epithelium. Cell 122, 449-459.

KENNAN, A., AHERNE, A., and HUMPHRIES, P. (2005). Light in retinitis pigmentosa. Trends Genet. 21, 103-110.

LAI, C.M., YU, M.J., BRANKOV, M., BARNETT, N.L., ZHOU, X., REDMOND, T.M., NARFSTROM, K., and RAKOCZY, P.E. (2004). Recombinant adeno-associated virus type 2-mediated gene delivery into the Rpe $65^{-/-}$knockout mouse eye results in limited rescue. Genet. Vaccines Ther. 2, 3.

LA VAIL, M.M., YASUMURA, D., MATTHES, M.T., DRESNER, K.A., FLANNERY, J.G., LEWIN, A.S., and HAUSWIRTH, W.W. (2000). Ribozyme rescue of photoreceptor cells in P23H transgenic rats: Long-term survival and late-stage therapy. Proc. Natl. Acad. Sci. U.S.A. 97, 11488-11493. 
LE MEUR, G., WEBER, M., PEREON, Y., MENDES-MADEIRA, A., NIVARD, D., DESCHAMPS, J.Y., MOULLIER, P., and ROLLING, F. (2005). Postsurgical assessment and long-term safety of recombinant adeno-associated virus-mediated gene transfer into the retinas of dogs and primates. Arch. Ophthalmol. 123, 500-506.

LEUNG, I.Y., SANDSTROM, M.M., ZUCKER, C.L., NEURINGER, M., and MAX SNODDERLY, D. (2005). Nutritional manipulation of primate retinas. IV. Effects of $n-3$ fatty acids, lutein, and zeaxanthin on S-cones and rods in the foveal region. Exp. Eye Res. 81, 513-529.

MARMOR, M.F., HOLDER, G.E., SEELIGER, M.W., YAMAMOTO, S., and INTERNATIONAL SOCIETY FOR CLINICAL ELECTROPHYSIOLOGY OF VISION. Standard for clinical electroretinography (2004 update). Doc. Ophthalmol. 108, 107-114.

MOISEYEV, G., CHEN, Y., TAKAHASHI, Y., WU, B.X., and MA, J.X. (2005). RPE65 is the isomerohydrolase in the retinoid visual cycle. Proc. Natl. Acad. Sci. U.S.A. 102, 12413-12418.

NARFSTROM, K., KATZ, M.L., BRAGADOTTIR, R., SEELIGER, M., BOULANGER, A., REDMOND, T.M., CARO, L., LAI, C.M., and RAKOCZY, P.E. (2003). Functional and structural recovery of the retina after gene therapy in the RPE65 null mutation dog. Invest. Ophthalmol. Vis. Sci. 44, 1663-1672.

PANG, J.J., CHANG, B., KUMAR, A., NUSINOWITZ, S., NOORWEZ, S.M., LI, J., RANI, A., FOSTER, T.C., CHIODO, V.A., DOYLE, T., LI, H., MALHOTRA, R., TUSNER, J., MCDOWELL, J.H., MIN, S.H., LI, Q., KAUSHAL, S., and HAUSWIRTH, W.W. (2006). Gene therapy restores vision-dependent behavior as well as retinal structure and function in a mouse model of RPE65 Leber congenital amaurosis. Mol. Ther. 13, 565-572.

PAWLYK, B.S., SMITH, A.J., BUCH, P.K., ADAMIAN, M., HONG, D.H., SANDBERG, M.A., ALI, R.R., and LI, T. (2005). Gene replacement therapy rescues photoreceptor degeneration in a murine model of Leber congenital amaurosis lacking RPGRIP. Invest. Ophthalmol. Vis. Sci. 46, 3039-3045.

POLYAK, S.L. (1941). The Retina. (University Chicago Press, Chicago, IL).

PREISING, M.N., and HEEGAARD, S. (2004). Recent advances in early-onset severe retinal degeneration: More than just basic research. Trends Mol. Med. 10, 51-54.

PROVIS, J.M., PENFOLD, P.L., CORNISH, E.E., SANDERCOE, T.M., and MADIGAN, M.C. (2005). Anatomy and development of the macula: Specialisation and the vulnerability to macular degeneration. Clin. Exp. Optom. 88, 269-281.

PROVOST, N., LE MEUR, G., WEBER, M., MENDES-MADEIRA, A., PODEVIN, G., CHEREL, Y., COLLE, M.A., DESCHAMPS, J.Y., MOULLIER, P., and ROLLING, F. (2005). Biodistribution of rAAV vectors following intraocular administration: Evidence for the presence and persistence of vector DNA in the optic nerve and in the brain. Mol. Ther. 11, 275-283.
RANDO, R.R. (2001). The biochemistry of the visual cycle. Chem. Rev. 101, 1881-1896.

REDMOND, T.M., YU, S., LEE, E., BOK, D., HAMASAKI, D., CHEN, N., GOLETZ, P., MA, J.X., CROUCH, R.K., and PFEIFER, K. (1998). Rpe65 is necessary for production of 11-cis-vitamin A in the retinal visual cycle. Nat. Genet. 20, 344-351.

REDMOND, T.M., POLIAKOV, E., YU, S., TSAI, J.Y., LU, Z., and GENTLEMAN, S. (2005). Mutation of key residues of RPE65 abolishes its enzymatic role as isomerohydrolase in the visual cycle. Proc. Natl. Acad. Sci. U.S.A. 102, 13658-13663.

ROBERTS, J.A., CLAYTON, J.D., and SEIBOLD, H.R. (1972). The natural incidence of pyelonephritis in the nonhuman primate. Invest. Urol. 9, 276-281.

ROLLING, F. (2004). Recombinant AAV-mediated gene transfer to the retina: Gene therapy perspectives. Gene Ther. 11, S26-S32.

SKELTON-STROUD, P.N., and GLAISTER, J.R. (1987). Naturally occurring renal disease in non-human primates. In: P.H. Bach and E.A. Lock, eds. Nephrotoxicity in the Experimental and Clinical Situation. (Martinus Nijhoff, New York) pp. 189-210.

SONG, S., SCOTT-JORGENSEN, M., WANG, J., POIRIER, A., CRAWFORD, J., CAMPBELL-THOMPSON, M., and FLOTTE, T.R. (2002). Intramuscular administration of recombinant adeno-associated virus $2 \alpha-1$ antitrypsin (rAAV-SERPINA1) vectors in a nonhuman primate model: Safety and immunologic aspects. Mol. Ther. 6, 329-335.

SURACE, E.M., and AURICCHIO, A. (2003). Adeno-associated viral vectors for retinal gene transfer. Prog. Retin. Eye Res. 22, 705-719.

SZLYK, J.P., FISHMAN, G.A., GROVER, S., REVELINS, B.I., and DERLACKI, D.J. (1998). Difficulty in performing everyday activities in patients with juvenile macular dystrophies: Comparison with patients with retinitis pigmentosa. Br. J. Ophthalmol. 82, 1372-1376. THOMPSON, D.A., and GAL, A. (2003). Vitamin A metabolism in the retinal pigment epithelium: Genes, mutations, and diseases. Prog. Retin. Eye Res. 22, 683-703.

Address reprint requests to: Dr. Samuel G. Jacobson Scheie Eye Institute 51 N. 39th Street Philadelphia, PA 19104

E-mail: jacobsos@mail.med.upenn.edu

Received for publication March 29, 2006; accepted after revision July 5, 2006.

Published online: July 19, 2006. 